\title{
Editorial \\ Teaching medical education during the era of COVID-19 pandemic: challenges and probable solutions. Yousuf $R^{1}$ and Salam $A^{2}$
}

Keywords: COVID-19 pandemic; teaching medical education; challenges; probable solutions.

Bangladesh Journal of Medical Science, Special Issue on COVID-19. 2021. Page : 3-6 DOI: https://doi.org/10.3329/bjms.v20i5.55394

Medical education involves pre-clinical and clinical teaching to build a strong knowledge foundation and clinical experience for the medical students. Their physical presence in inpatient and outpatient clinical settings is imperative for the successful practice of early clinical experiences and the clerkship curriculum. ${ }^{1}$ However, the COVID-19 pandemic has caused substantial ramifications on the medical education system. This paper aims to critically evaluate the impact of the COVID-19 pandemic on medical education and to recommend possible solutions.

The severe contagious nature of the coronavirus SARS-CoV-2, its high mortality rate combined with a lack of knowledge of the virus pushed the world to change the daily lifestyle to isolation, staying at home, quarantine, wearing mask, social distancing by remaining two meters apart from others, and work from home, etc. ${ }^{1,2}$ Consequently, medical education is facing many challenges on teaching, assessment, and feedback to the students. The pandemic has also caused worldwide mental health anxiety, depression, and suicidal attempts. ${ }^{3}$ The pandemic has had grave repercussions on medical education in that the students have had reduced exposure to clinical specialties that would ultimately lead to a detrimental effect on their examination performance, confidence, and competency. ${ }^{4}$ Pre-clinical medical students face challenges as the face-to-face teaching and other hands-on training such as cadaveric dissections, practical sessions using physical aids such as bones, specimens, and models and laboratory classes cannot take place..$^{5-8}$

However, continuity of medical education is crucial to prepare future medical graduates. Therefore, the COVID-19 pandemic has now forced educators around the world to shift from face-to-face teaching to online teaching. ${ }^{9,10}$ Although online collaborative learning using a software platform such as "Wimba", "Adobe Connect", and other software had emerged earlier as a new educational paradigm, ${ }^{11-14}$ its use is now obligatory to continue the education. Teaching via online platforms is now practiced using platforms such as video conferencing by Google Meet, Zoom, Slack, Cisco WebEx, Microsoft Teams, and customizable cloud-based learning management platforms such as Elias and Moodle. ${ }^{15,16}$ The virtual teaching taking place through virtual web-based platforms consists of webinars, case discussions, reading assignments, and prerecorded virtual scenarios. ${ }^{2,17}$ Although, for clinical students, it is necessary to have the actual patient contact for learning and developing the skill for accurate diagnosis and management, this COVID-19 pandemic situation demands some extraordinary measures for the continuity of medical education. Telemedicine using a tablet computer by patients that are connected to both students and physicians is found as an effective method. ${ }^{18}$ Clinical teaching by virtual bedside rounds were practiced with COVID-19 patients where the attending physician attached an iPad Pro to a computer to share important diagnostic findings through video

1. Rabeya Yousuf ${ }^{1}$, Blood Bank Unit, Department of Diagnostic Laboratory Services, Universiti Kebangsaan Malaysia (UKM) Medical Centre, Hospital Canselor Tuanku Muhriz UKM, Malaysia

2. Abdus Salam ${ }^{2}$, Medical Education and Community Medicine Unit, Faculty of Medicine, Widad University College, Malaysia

Correspondence: Dr. Abdus Salam, Associate Professor and Head of Medical Education and Community Medicine Unit, Manager Curriculum and Academic-Scheduling, Faculty of Medicine, Widad University College, Bandar Indera Mahkota, 25200 Kuantan, Pahang, Malaysia.

Email: abdussalam.dr@gmail.com ORCID ID: https://orcid.org/0000-0003-0266-9747 
conferencing with the students. Medical students observed the attending physician-patient encounter and also interact with patients; a large number of students recommended this form of teaching and agreed that it stimulated learning. ${ }^{19}$ Adoption of virtual patients built with artificial intelligence that simulates real-life clinical scenarios and allows the learners to obtain clinical history, perform a physical examination, investigation, and to reach a diagnosis and therapeutic decisions was found useful and met the expectations of most students. ${ }^{20}$

Thus, the COVID-19 pandemic situation has transformed the medical curriculum to web-based virtual platforms and showed increased class attendance by the students due to easiness of access, and their anonymity makes them comfortable in asking questions that increase student engagement. There are also accessible free webinars that allow the exchange of ideas. ${ }^{21}$ However, many challenges are faced that include technical challenges such as lack of reliable network infrastructure, problems with hardware and software, compatible online platforms, and increased cost. Poor computer skills of the faculty and students only add to the problem. ${ }^{2}$ Thus, faculty need to give extra time and effort to prepare the online modules. The challenges are more severe for low-income and middle-income countries due to inadequate infrastructure including unstable bandwidth causing the low quality of audio and video outputs and slow download speed, frequent electrical power failures, and a lack of resources and support for this online platform teaching. ${ }^{22}$ There are also reports of lack of student engagement due to attention deficit, multitasking during attending sessions, poor audio and video quality, internet issues, etc., and it is also difficult to conduct a secure and valid online assessment. ${ }^{8}$

For the transformation to online teaching-learning, Reyna $(2020)^{23}$ has provided few guidelines for the faculties. It is suggested to engage students as partners in the learning process, use weekly video vignettes to create online teacher presence by describing the learning outcomes of the week, and inform how students will learn. This will make the contents credible and engaging for students. While delivering the actual online class, having an interactive module by presenting content, worked examples such as case scenarios, activities such as the multiple-choice question, and feedbacks will augment the learning experiences. It is necessary to have an appropriate visual design. The use of flipped learning by asking students to prepare before their online lecture will help more student engagement. Use of webinars for delivering tutorials, proper assessment, and feedback, and modeling students' self-regulation is the other important strategies. ${ }^{23}$

Assessment and teaching are two sides of the same coin; assessment drives learning and learning drives practice. So, assessment of students' learning is an integral part of medical education to ensure the quality of future doctors. ${ }^{24}$ As the COVID-19 pandemic causes shifting of teaching to online, the assessment also shifts to online. Institutional support with a stable learning management system (LMS) is crucial to carry out the online assessment. It can be done either by open book open web (OBOW) test which needs to be completed within a fixed time or by continuous assessment where a total of all assessments determines the final marks. ${ }^{16}$ To conduct a secure and valid online assessment, the use of software such as Proctorio Google Chrome extension can be beneficial as it monitors the students during the online examination. ${ }^{8}$ It is required to build and maintain an information technology (IT) infrastructure with well-trained IT expertise for the smooth running of the virtual classes and to provide training to faculty on the technological aspects to enable them to create, produce and present the online educational materials. ${ }^{1}$

In addition, faculty needs appropriate training on the teaching process, especially in terms of how to approach students. ${ }^{25}$ Here, communication is an important issue; faculty needs to adopt a tell, explain and assess (TEA) approach. Tell the students at the beginning what is going to be taught and more importantly why is it going to be taught, explain the teaching materials using relevant examples and media, and finally assess how much the students have comprehended what has been told and explained. Depending on the assessment results, faculty may need to reshape their strategy. ${ }^{10,26}$

Students were found to have psychological unrest during the COVID-19 pandemic and thus psychological support is very much essential for them to achieve their learning activities. ${ }^{27}$ Thus, it is essential to motivate the students by giving proper counseling and support in their education during this pandemic period. ${ }^{1}$

In conclusion, careful planning and well coordination in teaching delivery with the aid of educational technology is recommended for successful online collaborative learning. The faculty and students are required to be prepared to use software technology with proper training to increase their confidence level 
and thereby to help them to change their mindset to accept the technological development. At the same time, intradepartmental, interdepartmental, and full institutional management support is crucial. $^{28}$ The ongoing efforts by the educators, institutes, and students to overcome the deficits during the era of COVID-19 may transform medical education into a whole new level.
Funding

Nil.

\section{Conflict of Interest}

There are no conflicts of interest.

\section{Authors' Contribution}

Rabeya Yousuf conceived, designed, drafted, revised and approved the final version of the paper for submission. Abdus Salam critiques for important intellectual content and approved the final version for submission to Journal.

\section{Reference}

1. Jiang Z, Wu H, Cheng H, Wang W, Xie A, Fitzgerald SR. Twelve tips for teaching medical students online under COVID-19. Medical Education Online 2021; 26:1. doi: 10.1080/10872981.2020.1854066

2. Wilcha RJ. Effectiveness of Virtual Medical Teaching During the COVID-19 Crisis: Systematic Review. JMIR Med Educ 2020; 6(2): e20963). doi: 10.2196/20963

3. Khatoon F, Singh A, Jilani AQ, Ahmad A, Haq M, Pandey S. COVID-19 Pandemic and Mental Health of Doctors: An Observational Analytical Study from a Dedicated COVID Hospital. International Journal of Human and Health Sciences 2021; 5(3): 297-306. doi: org/10.31344/ijhhs.v5i3.279.

4. Ahmed H, Allaf M, Elghazaly H. COVID-19 and medical education. Lancet Infectious Disease 2020;20(7):777778. doi:10.1016/s1473-3099(20)30226-7

5. Singal A, Bansal A, Chaudhary P. Cadaverless anatomy: Darkness in the times of pandemic Covid-19. Morphologie 2020; 104(346): 147-150. doi: 10.1016/j.morpho.2020.05.003

6. Bianchi S, Gatto R, Fabiani L. Effects of the SARS$\mathrm{CoV}-2$ pandemic on medical education in Italy: considerations and tips. Euro Mediterranean Biomedical Journal 2020;15(24):100-101. doi: 10.3269/19705492.2020.15.24

7. Shahrvini B, Baxter SL, Coffey CS, Bridget V. MacDonald BV, Lander L. Pre-clinical remote undergraduate medical education during the COVID-19 pandemic: a survey study. BMC Medical Education 2021; 21: 13. doi: org/10.1186/s12909-020-02445-2.

8. Gupta N, Pandey S, Anshu A. Innovative Anatomy assessment methods in COVID-19 Pandemic: statistical observations and students' viewpoints. Bangladesh Journal of Medical Science 2020; 19: S21-S27. doi: 10.3329/bjms.v19i0.47831 
Bangladesh Journal of Medical Science, Vol : 20 Special Issue on Covid19, 2021

9. Roslan NS, and Halim AS. Enablers and Barriers to Online Learning among Medical Students during COVID-19 Pandemic: An Explanatory Mixed-Method Study. Sustainability 2021; 13: 6086. doi: org/10.3390/ su13116086.

10. Salam A. Best teaching method used, very good in teaching, the best lecturer ever: secrets of teaching online during Covid-19 pandemic. International Journal of Human and Health Sciences 2021; 05(04):271-275. doi: org/10.31344/ijhhs.v5i3.275

11. Salam A, Ibrahim NM, Kamaruddin MA, Besar MNA, Siraj HH, Mohamad N, Mahdy ZA, Ali RA, Saim L. Technology enhanced global online collaborative networking using MedEdWorld Wimba: UKM medical centres' experience. International Medical Journal 2011a; 18((2):107-109

12. Salam A, Aziz NA, Arif K, Harlina HS, Nabishah M, Norhayati M, Saim L. MedEdWorld online global collaborative learning network using Adobe Connect: An experience of Universiti Kabangsaan Malaysian Medical Centre. Medical Education Online [serial online] 2009;14 doi:10.3885/meo.2009.L0000028

13. Soekartawi. Effectiveness of Collaborative Learning in Online Teaching. Malaysian Online Journal of Instructional Technology 2006; 3:68-77.

14. Tim SR. Online Collaborative Learning: Theory and Practice. Information Science Publishing (Idea Group Inc.) USA, UK, 2004.

15. Kaup S, Jain R, Shivalli S, Pandey S, Kaup S. Sustaining academics during COVID-19 pandemic: The role of online teaching-learning. Indian Journal of Ophthalmology 2020; 68(6):1220-1221. doi: 10.4103/ ijo.IJO_1241_20.

16. Rashid A, Rashid MR, Yaman M N, Mohamad I. Teaching Medicine Online During the COVID-19 Pandemic: A Malaysian Perspective. Bangladesh Journal of Medical Science 2020; 19: S 77-S 81. doi:10.3329/ bjms.v19i0.48170

17. Garg T, Shrigiriwar A, Patel K. Trainee education during COVID-19. Neuroradiology 2020; 62:1057-1058 (online). doi: org/10.1007/s00234-020-02478-w

18. Mian A, Khan S. Medical education during pandemics: a UK perspective. BMC Medicine 2020; 18:100. doi: org/10.1186/s12916-020-01577-y

19. Hofmann H, Harding C, Youm J, Wiechmann W. Virtual bedside teaching rounds with patients with COVID-19. Medical Education 2020; 54(10):959-960. doi:10.1111/ $\underline{\text { medu. } 14223}$

20. De Ponti R, Marazzato J, Maresca AM. Rovera F, Carcano G, Ferrario MM. Pre-graduation medical training including virtual reality during
COVID-19 pandemic: a report on students' perception. BMC Medical Education 2020; 20: 332. doi: org/10.1186/s12909-020-02245-8

21. Dafli E, Fountoukidis I, Hatzisevastou-Loukidou C, Bamidis PD. Curricular integration of virtual patients: a unifying perspective of medical teachers and students. BMC Medical Education 2019; 19: 416. doi: org/10.1186/ s12909-019-1849-7.

22. Dawidziuk A, Kawka M, Szyszka B, Wadunde I, Ghimire A. Global Access to Technology-Enhanced Medical Education During the COVID-19 Pandemic: The Role of Students in Narrowing the Gap. Global Health: Science and Practice 2021; 9(1):10-14. doi:10.9745/ GHSP-D-20-00455

23. Reyna J. Twelve Tips for COVID-19 friendly learning design in medical education. Med Ed Publish 2020; 9(1):103. doi: 10.15694/mep.2020.000103.1

24. Salam A, Yousuf R, Abu Bakar SM. Multiple Choice Questions in Medical Education: How to Construct High Quality Questions. International Journal of Human and Health Sciences 2020; 4(2): 79-88. doi: 10.31344/ijhhs. v4i2.180

25. Kamarudin MA, Md Shah S-AM, Ismail NAS, Yen TP, Shamsul AS, Che Razali HI, Salam A. Perceptions of mentors and mentees towards the mentoring system at the Universiti Kebangsaan Malaysia Medical Centre. Education in Medicine Journal 2021;13(2):55-70. doi: org/10.21315/eimj2021.13.2.5

26. Zainol J, Salam A. An Audit on Mentor-Mentee Program: Mentees Perceptions on Mentors. Bangladesh Journal of Medical Science 2021; 20(04): 840-847 doi: org/10.3329/bjms.v20i4.54143

27. Rahali K, Abidli Z, Khohmimidi A, Elhamzaoui M, Seghiri R, Jabari K, et al. Ibn Tofail's University students' satisfaction evaluation towards distance learning and its impacts on the students' mental health during the COVID-19 Confinement. Bangladesh Journal of Medical Science 2020; 19: S51-S57. doi: 10.3329/bjms. $\underline{\mathrm{v} 19 \mathrm{i} 0.48166}$

28. Salam A, Ghafar AA, Latif HA, Siraj HH, Mahdy ZA, Zakaria SZS, Mohamad N, Ali RA. Synchronous transnational collaborative learning: An interesting model of education to learn medicine in global perspectives. South East Asia Journal of Public Health 2011b; 1:59-63. 